\title{
Epidural anaesthesia restores pancreatic microcirculation and decreases the severity of acute pancreatitis
}

\author{
Alp Demirag, Catherine M Pastor, Philippe Morel, Copin Jean-Christophe, Andreas W Sielenkämper, \\ Nilgun Güvener, Gang Mai, Thierry Berney, Jean-Louis Frossard, Leo H Bühler
}

Alp Demirag, Catherine M Pastor, Philippe Morel, Nilgun Güvener, Gang Mai, Thierry Berney, Leo H Bühler, Surgical Research Unit, Department of Surgery, University Hospital Geneva, 24, Rue Micheli-du-Crest, 1211, Geneva 14, Switzerland Catherine M Pastor, Copin Jean-Christophe, Jean-Louis Frossard, Division of Gastroenterology, Department of Internal Medicine, University Hospital Geneva, 24, Rue Micheli-du-Crest, 1211, Geneva 14, Switzerland

Andreas W. Sielenkämper, Department of Anaesthesiology and Intensive Care Medicine, Münster, Germany

Gang Mai, Department of General Surgery, West China Hospital, Sichuan University, Chengdu 610041, Sichuan Province, China Co-correspondence: Jean-Louis Frossard

Correspondence to: Leo H Bühler, MD, Surgical Research Unit, Department of Surgery, University Hospital Geneva, 24, Rue Micheli-du-Crest, 1211, Geneva 14,

Switzerland. leo.buhler@hcuge.ch

Telephone: +41-22-3727698 Fax: +41-22-3727689

Received: 2005-02-21 Accepted: 2005-04-30

\begin{abstract}
AIM: To investigate the effect of epidural anaesthesia (EA) on pancreatic microcirculation during acute pancreatitis (AP).
\end{abstract}

METHODS: AP was induced by injection of sodium taurocholate into the pancreatic duct of Sprague-Dawley rats. To realize EA, a catheter was introduced into the epidural space between T7 and T9 and bupivacaine was injected. Microcirculatory flow was measured by laser Doppler flowmetry. Arterial blood gas analyses were performed. At the end of the experiment $(\leqslant 5 \mathrm{~h})$, pancreas was removed for histology. The animals were divided into three groups: Group $1(n=9)$, AP without EA; Group $2(n=4)$, EA without AP; and Group $3(n=6)$, AP treated by EA.

RESULTS: In Group 1, pancreatic microcirculatory flow prior to AP was $141 \pm 39$ perfusion units (PU). After AP, microcirculatory flow obviously decreased to $9 \pm 6 \mathrm{PU}$ $(P<0.05)$. Metabolic acidosis developed with base excess (BE) of - $14 \pm 3 \mathrm{mmol} / \mathrm{L}$. Histology revealed extensive edema and tissue necrosis. In Group 2, EA did not significantly modify microcirculatory flow. BE remained unchanged and histological analysis showed normal pancreatic tissue. In Group 3, AP initially caused a significant decrease in microcirculatory flow from $155 \pm 25$ to $11 \pm 7$ PU $(P<0.05)$. After initiation of EA, microcirculatory flow obviously increased again to $81 \pm 31 \mathrm{PU}(P<0.05)$. BE was $-6 \pm 4 \mathrm{mmol} / \mathrm{L}$, which was significantly different compared to Group $1(P<0.05)$. Furthermore, histology revealed less extensive edema and necrosis in pancreatic tissue in Group 3 than that in Group 1.

CONCLUSION: AP caused dramatic microcirculatory changes within the pancreas, with development of metabolic acidosis and tissue necrosis. EA allowed partial restoration of microcirculatory flow and prevented development of tissue necrosis and systemic complications. Therefore, EA should be considered as therapeutic option to prevent evolution from edematous to necrotic AP.

(c) 2006 The WJG Press. All rights reserved.

Key words: Acute pancreatitis; Epidural anaesthesia; Pancreatic blood flow; Microcirculation; Taurocholic acid

Demirag A, Pastor CM, Morel P, Jean-Christophe C, Sielenkämper AW, Güvener N, Mai G, Berney T, Frossard JL, Bühler LH. Epidural anaesthesia restores pancreatic microcirculation and decreases the severity of acute pancreatitis. World J Gastroenterol 2006; 12(6): 915-920

http://www.wjgnet.com/1007-9327/12/915.asp

\section{INTRODUCTION}

Among patients suffering from acute pancreatitis (AP), $80 \%$ have a favorable evolution and approximately $20 \%$ develop a severe disease with significant morbidity and mortality ${ }^{[1]}$. Severe AP is associated with the development of local complications, such as pancreatic and peripancreatic necrosis, abscesses or pseudocysts, and systemic complications, such as adult respiratory distress syndrome or renal failure with a mortality close to $15 \%{ }^{[2]}$.

The pathophysiology of AP is incompletely understood but alteration in the pancreatic microcirculatory blood flow has been involved. Thus, a decrease in pancreatic blood flow occurs early in the course of AP and has been suggested to play a role in the conversion of edematous to necrotizing $\mathrm{AP}^{[3-7]}$. The microcirculatory dysfunction includes arterial vasoconstriction with hypoperfusion, ischemia-reperfusion injury, and obstruction of the venous outflow ${ }^{[8-11]}$. Other factors that participate in the development of microcirculatory 
dysfunction are hemoconcentration, hypercoagulability, and increase in microvascular permeability ${ }^{[8-11]}$. Besides perfusion abnormalities, AP is also characterized by local and systemic inflammatory responses, including leukocyte activation as well as release of free radicals and cytokines $^{[12-14]}$.

Many therapeutic agents, such as dextran, heparin, procaine, L-arginine, antioxidants, or cytokine antagonists, have been tested experimentally and/or clinically to improve pancreatic tissue perfusion during AP, however, no significantly successful result has been achieved $^{[1,4,15-18]}$.

Epidural anesthesia (EA) that is used to induce analgesia in the perioperative period might be an interesting treatment of the microcirculatory blood flow abnormalities. Thus, EA can reduce the incidence of post-operative pulmonary complications, and shorten the duration of the post-operative intestinal paralysis ${ }^{[19,20]}$. In addition, experimental studies have shown that EA increases gut mucosal blood flow and delays the metabolic acidosis due to intestinal ischemia in the presence of a decreased perfusion pressure ${ }^{[21-22]}$. The beneficial effect of EA has been attributed to a sympathetic nerve blockade, which redistributes blood flow to the non-perfused regions of the gut ${ }^{[21]}$. Additionally, EA is useful to decrease pain in patients with $\mathrm{AP}^{[23]}$, but no study has investigated the effects of EA on the pancreatic microcirculatory blood flow during AP.

Because we postulated that EA might improve the pancreatic hypoperfusion induced by AP and concomitantly decrease the severity of the disease, we measured the pancreatic microcirculatory blood flow and the severity of the disease in rats injected with taurocholic acid in the biliopancreatic duct, in the presence or in the absence of EA.

\section{MATERIALS AND METHODS}

\section{Animals}

Adult male Wistar rats (275-300 g) were provided by Charles River (L'Arbresle, France). Animals were bred and housed in standard cages and maintained in climatecontrolled rooms. Animals were fed with standard laboratory chow, given water ad libitum, and randomly assigned to control or treated groups. The protocol was approved by the Animal Ethical Committee of the Geneva University Medical School and by the Geneva Veterinary Authorities.

\section{Epidural anaesthesia}

Epidural catheters were placed in rats under isoflurane anesthesia. A polyethylene catheter (PE10, Portex, Kent, UK) was introduced in the lumbar region and positioned into the epidural region between $\mathrm{T} 7$ and $\mathrm{T} 9$ according to the technique previously described by Grouls $e t a^{[24]}$. The external end of the catheter was tunneled subcutaneously and fixed to the occiput.

The animals were allowed to recover from anesthesia and $1 \mathrm{~h}$ after epidural catheterization, bupivacaine $(4 \mathrm{~g} / \mathrm{L}, 20 \mu \mathrm{L})$ was injected to test anaesthesia. Hind limb muscle tone was scored by manual inspection and visual observation as previously described during $30 \mathrm{~min}^{[21,24]}$. A normal tone with free movement of the hind limbs was scored 0 ; weak hypotonia of the hind limbs and of the body was scored 1; moderate hypotonia of the hind limbs and of the body was scored 2; and inability to support the body on the hind limbs and flat body posture was scored 3 . After scoring, rats were allowed to recover for $2 \mathrm{~h}$. Animals showing signs of neurologic damage were discarded. To verify the position of the catheter, after rat sacrifice, Evans blue solution was injected in the catheter and the spinal column exposed. Animals that had the catheter tip located intrathecally or outside the region between T7 - T9 were excluded from the study.

\section{Surgical preparation}

Anaesthesia was induced by pentobarbital sodium (50 $\mathrm{mg} / \mathrm{kg}$ intraperitoneally) and isoflurane inhalation. Rats had tracheotomy under isoflurane anesthesia and were mechanically ventilated (Harvard apparatus, model 683, South Natick, MA) with a Fio2 $=0.5$. The left femoral vein was cannulated and continuously perfused with saline solution $(2.5 \mathrm{~mL} / 100 \mathrm{~g} / \mathrm{h})$. The left femoral artery was cannulated for continuous monitoring of arterial blood pressure and blood gas analysis (ABL 505 Analyzer, Radiometer, Copenhagen, Denmark). Body temperature was kept constant with a warm pad.

Blood samples were harvested every $30 \mathrm{~min}$ for blood gas analysis and ventilation was adjusted to obtain $\mathrm{pCO}_{2}$ between 35 and $45 \mathrm{mmHg}$. The blood samples were also analyzed for serum amylase concentrations using 4,6-ethylidene (G1)-p-nitrophenyl (G1)- $\alpha$ aD-maltoheptoside (Sigma Chemical Co, Zurich, Switzerland) as substrate. Mean arterial pressure was continuously recorded and stored via an analog-digital interface converter (Biopac, Santa Barbara, CA) on an AST microcomputer (AST, Limerick, Ireland).

\section{Induction of acute pancreatitis}

After laparotomy, the pancreatic duct was cannulated with a 22-gauge catheter (Abott, Sligo, Ireland) ${ }^{[25]}$. A clip was placed on the pancreatic duct close to the liver and taurocholic acid $(5 \%, 500 \mu \mathrm{L}$, Sigma, Saint-Louis, MO) was infused over 4 min with a micropump ${ }^{[25]}$.

\section{Pancreatic microcirculatory blood flow}

Pancreatic microcirculatory blood flow was measured with a laser Doppler flowmetry (Periflux system 5000, Perimed AB, Järfälla, Sweden). To position the probe, a latex adhesive probe miniholder (model PH07, Perimed, Järfälla, Sweden) and a special articulated laboratory stand were used. The Doppler probe was placed under the pancreatic surface with the light directed upward. After a 10 to 15 min stabilization period, the effect of AP and/or EA on the pancreatic microcirculatory blood flow was measured over time. The pancreatic microcirculatory blood flow was continuously recorded and stored via an analogdigital interface converter (Biopac, Santa Barbara, CA) on an AST microcomputer (AST, Limerick, Ireland).

\section{Tissue samples}

After the rats were sacrificed, pancreatic samples were rapidly collected, fixed in formalin, embedded in paraffin, 


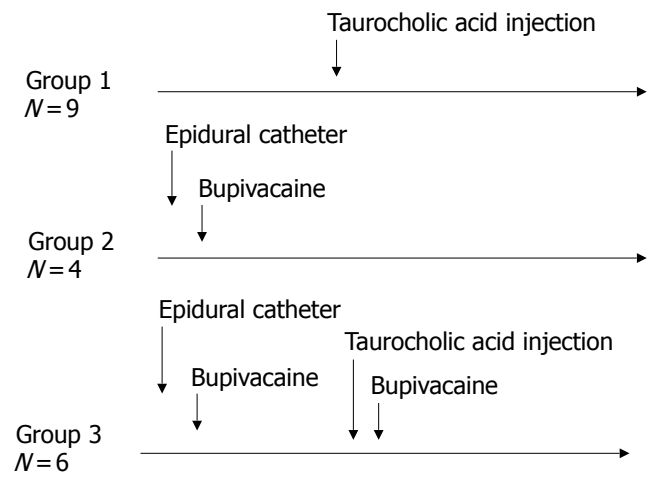

Figure 1 Experimental design. Acute pancreatitis was induced in Groups 1 and 3 by injection of taurocholic acid $(5 \%, 500 \mu \mathrm{L})$ into the biliopancreatic duct. Epidural anesthesia was induced in Groups 2 and 3 by epidural injection of bupivacaine $(4 \mathrm{~g} / \mathrm{L}, 20 \mu \mathrm{L})$.

and cut into $5-\mu \mathrm{m}$ thick sections. After staining with hematoxylin-eosin, the sections were examined by two experienced morphologists who were not aware of the sample identity. The extent of acinar cell necrosis was quantified by computer assisted morphometry as previously described $^{[26]}$ and expressed as a percent of total acinar tissue.

\section{Experimental design}

Three experimental groups were studied (Figure 1). In Group $1(n=9)$, rats had AP induction and no EA. Pancreatic microcirculatory blood flow was measured before taurocholic acid injection and continued after the induction of AP. In Group $2(n=4)$, the pancreatic microcirculatory blood flow was determined before and continued after the induction of EA. In Group 3 $(n=6), 30 \mathrm{~min}$ after taurocholic acid injection, bupivacaine was injected via the epidural catheter and the pancreatic microcirculatory blood flow measured over time.

\section{Statistical analysis}

Results were expressed as mean \pm SD. Nonparametric Wilcoxon Signed ranks test and Kruskal-Walis tests for comparison between groups were used as appropriate. $P<0.05$ was considered statistically significant.

\section{RESULTS}

\section{Epidural anesthesia in rats}

EA was tested by bupivacaine injection in Groups 2 and

3. In all rats, hind limb blockade was complete within

2 min and the motility completely recovered within 25-30 min after the injection. In Group 3, rats had taurocholic acid injection to induce AP and were treated with bupivacaine (Figure 1).

\section{Pancreatic microcirculatory blood flow}

In Group 1, induction of AP caused a significant decrease of mean pancreatic microcirculatory blood flow from $141 \pm 40$ units to $9 \pm 6$ units $(96 \%, P=0.008)$ within $30 \mathrm{~min}$ (Figure 2). The decreased blood flow remained unchanged until the end of the experiment. In Group 2, EA slightly increased microcirculatory blood flow, but the
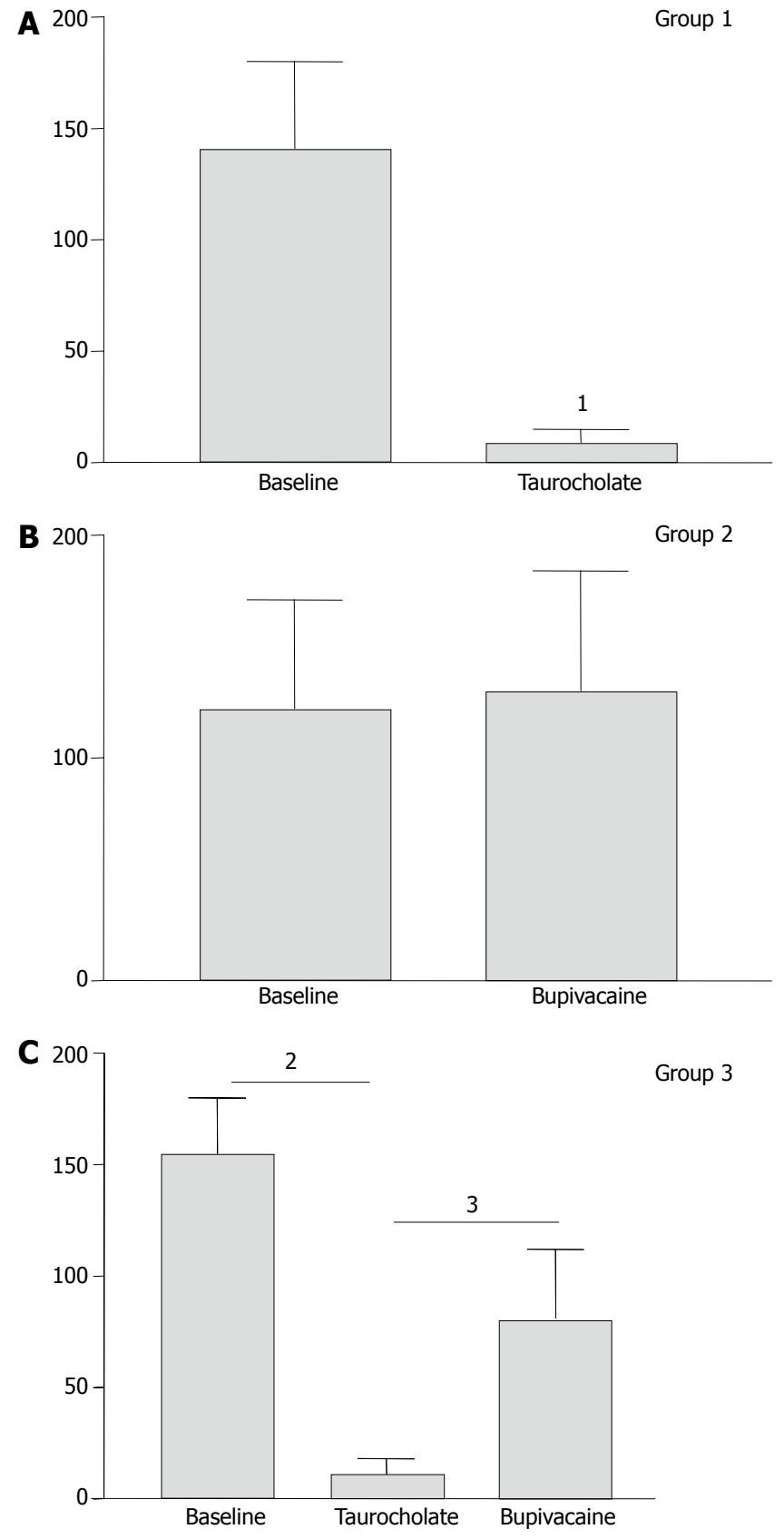

Figure 2 Pancreatic microcirculatory blood flow (arbitrary units). In Group 1, the mean value of pancreatic blood flow measured prior to and after induction of AP showed a significant decrease of perfusion from $141 \pm 40$ units to $9 \pm 6$ units $(96 \%)\left({ }^{1} P=0.008\right)$ within $30 \mathrm{~min}$. In Group 2, the mean value of pancreatic blood flow measured prior to and after induction of epidural anaesthesia showed no significant modification of perfusion. In Group 3, mean value of pancreatic blood flow measured prior to and after induction of $\mathrm{AP}$, and epidural anaesthesia, respectively. Induction of AP caused a significant decrease in pancreatic microcirculatory flow from $155 \pm 25$ units to $11 \pm 7$ units $(93 \%)\left({ }^{2} P=0.004\right)$. After induction of epidural anesthesia, mean pancreatic microcirculatory blood flow increased again significantly to $81 \pm 31$ units within $45 \mathrm{~min}$, reaching $52 \%$ of base line values $\left({ }^{3} P=0.028\right)$.

modification did not reach statistical significance $(P=0.7$, Figure 2). In Group 3, induction of AP caused a similar decrease in pancreatic microcirculatory flow as in Group 1, i.e., from $155 \pm 25$ units to $11 \pm 7$ units $(93 \%, P=0.004)$. After induction of EA, mean pancreatic microcirculatory blood flow increased again significantly to $81 \pm 31$ units within $45 \mathrm{~min}$, reaching $52 \%$ of baseline values $(P=0.028$, Figures 2 and 3). 


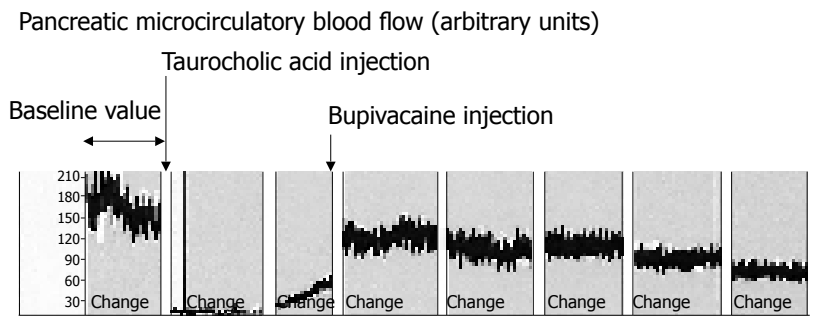

Figure 3 Recording of pancreatic microcirculatory blood flow in Group 3. Rats were injected with taurocholic acid and treated $30 \mathrm{~min}$ later with bupivacaine $(0.4 \%$, $20 \mu \mathrm{L}$ ) in the epidural catheter. Induction of AP caused a significant decrease in pancreatic microcirculatory blood flow. After induction of epidural anesthesia, mean pancreatic microcirculatory blood flow increased again significantly within 45 min, reaching approximately $50 \%$ of baseline values.

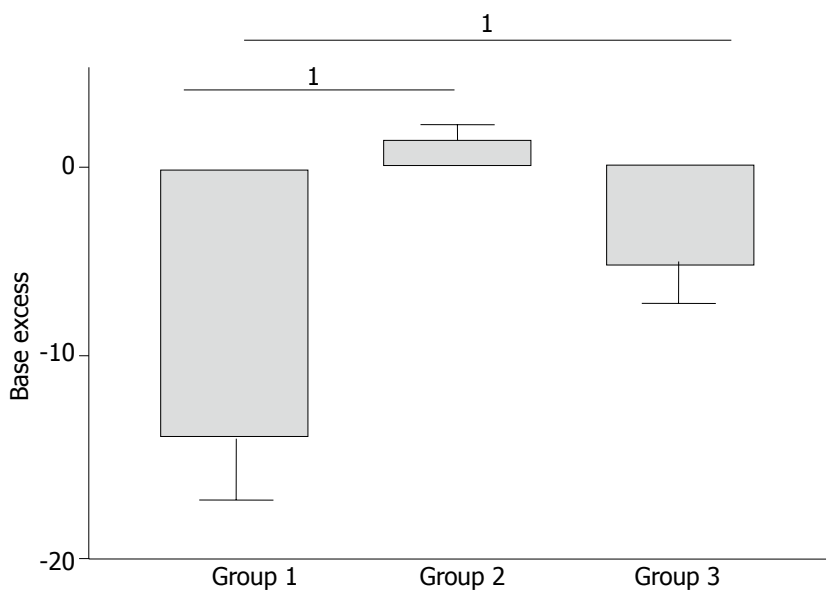

Figure 4 Arterial blood gas analyses. In Group 1, severe metabolic acidosis developed progressively reaching a maximum base excess $(B E)$ value of $-14 \pm 3$ $\mathrm{mmol} / \mathrm{L}$ at the end of the experiment. In Group 2, BE values remained unchanged compared to baseline values. In Group 3, a mild metabolic acidosis developed reaching a maximum $B E$ value of $-6 \pm 4 \mathrm{mmol} / \mathrm{L}$ at the end of the experiment. This result was significantly improved compared to Group $1\left({ }^{1} P=0.007\right)$.

\section{Arterial blood gas and serum amylase analyses}

In Group 1, severe metabolic acidosis developed progressively reaching a maximum base excess $(\mathrm{BE})$ value of $-14 \pm 3 \mathrm{mmol} / \mathrm{L}$ at the end of the experiment (Figure 4). In Group 2, BE values remained unchanged compared to the baseline values during experiment (Figure 4). In Group 3, a mild metabolic acidosis developed reaching a maximum $\mathrm{BE}$ value of $-6 \pm 4 \mathrm{mmol} / \mathrm{L}$ at the end of the experiment (Figure 4). This result was significantly improved compared to Group $1(P=0.007)$.

In Group 1, serum amylase levels increased from $694 \pm 419$ units / L prior to AP to $2178 \pm 561$ units/L $(P<0.05)$ after $2 \mathrm{~h}$ of induction of AP (Figure 5). In Group 2, EA did not modify serum amylase level significantly during the experiment. In Group 3, serum amylase levels increased to a maximum of $1829 \pm 641$ units/L $2 \mathrm{~h}$ after initiation of AP and EA (Figure 5). Although this result was lower compared to Group 1, but did not reach statistical significance.

\section{Histopathology}

In Group 1, histopathology revealed a severe form of AP with extensive edema and tissue necrosis (Figure 6C). In

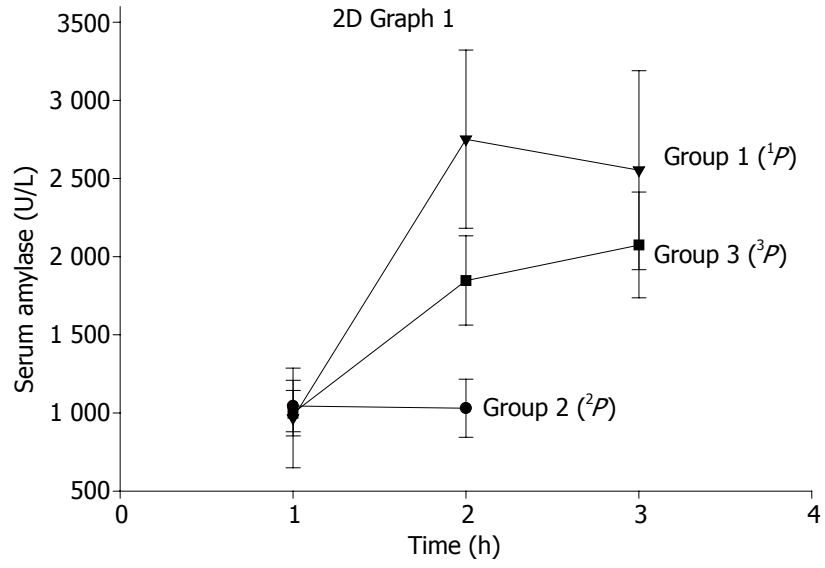

Figure 5 Serum amylase levels. In Group 1, serum amylase levels increased from $694 \pm$ units/L 419 prior to AP to $2178 \pm 561$ units/L $\left({ }^{1} P<0.05\right.$, vs serum amylase levels before induction of AP) after $2 \mathrm{~h}$ of induction of AP. In Group 2, epidural anaesthesia did not modify serum amylase levels significantly $(P=0.9)$. In Group 3 , serum amylase levels increased to a maximum of $1829 \pm 641$ units $/ L$ after $2 \mathrm{~h}$ of initiation of AP and epidural anesthesia. Although this result was lower compared to Group 1, but did not reach statistical significance $\left({ }^{3} P=0.08\right)$.

Group 2, almost normal pancreatic tissue was observed at the end of the experiment (Figure 6B). In Group 3, edema and necrosis were less extensive compared to animals in Group 1 (Figure 6D).

The extent of acinar cell necrosis measured as percentage of total surface at high power field (HPF) showed that Group 2 animals had similar cell necrosis as the controls ( $<10 \%$ ) (Figure 7$)$. Group 1 animals demonstrated over $40 \%$ of acinar cell necrosis at HPF, whereas acinar cell necrosis was below $30 \%$ in Group 3 animals (Figure 7).

\section{DISCUSSION}

In our study, taurocholic acid injection in the biliopancreatic duct induced a pancreatic hypoperfusion as reported by previous studies ${ }^{[3,7,16,25]}$. The decrease was $-96 \%$ within $15 \mathrm{~min}$ and pancreatic microcirculatory blood flow remained low until the end of the experiment. The microcirculatory blood flow has been accurately measured by laser Doppler flowmetry. The technique is ideal for monitoring changes in tissue perfusion over time and has successfully been applied to numerous organs in experimental and human studies ${ }^{[4,6,24,27]}$. However, several factors, such as artifacts induced by respiration, external light exposure and temperature, can affect the interpretation of the laser Doppler signals ${ }^{[4]}$. In addition, microcirculatory flow can vary widely over short distances, and small changes in probe angle during measurement can alter the measured values. To prevent these technical problems, we used a new type of probe holder, which allows the tissue to be maintained by gravity, avoiding repeated repositioning of the probe.

More importantly, we showed that after induction of $\mathrm{AP}$, bupivacaine injection in the epidural catheter increased pancreatic microcirculatory blood flow. Concomitantly, the improved microcirculatory blood flow within the pancreas decreased the severity of AP. Serum amylase 


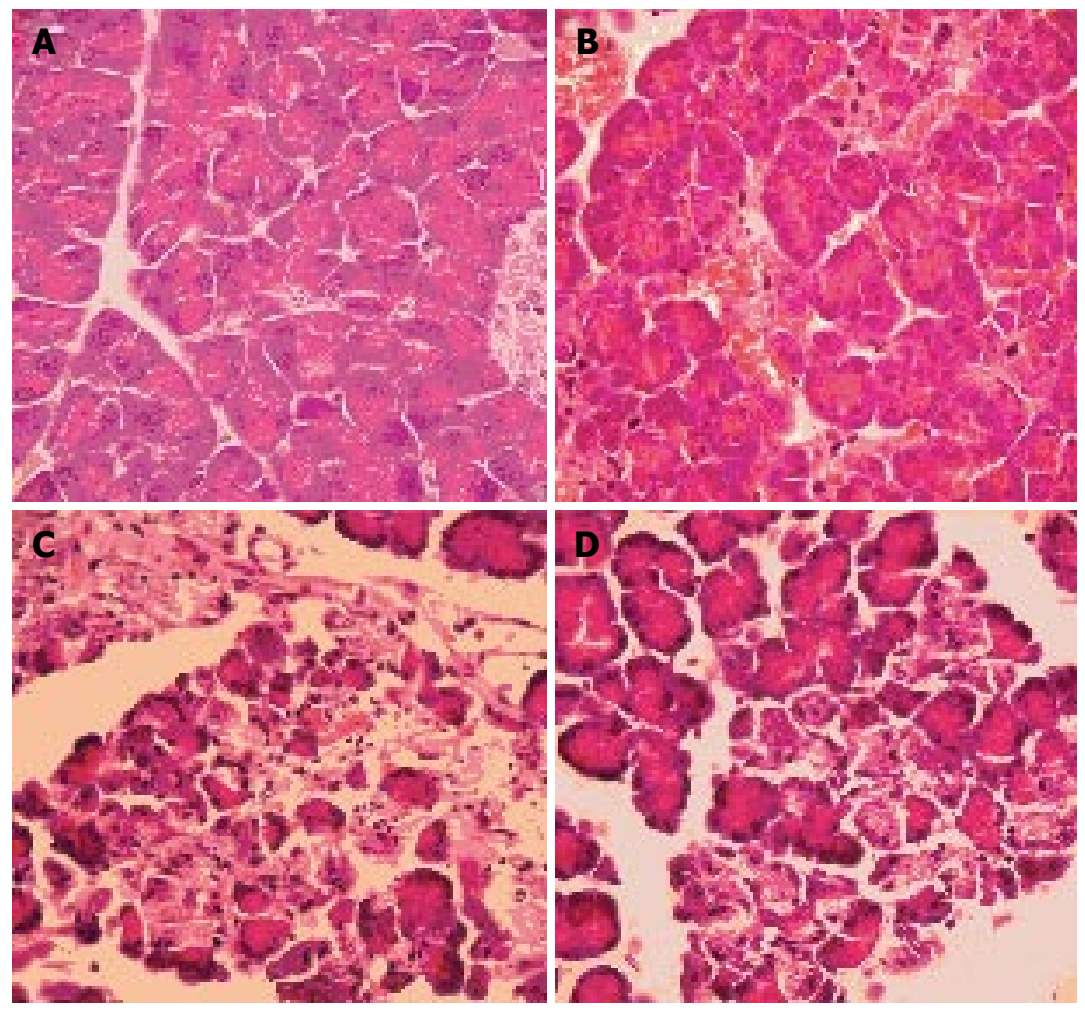

Figure 6 Histopathological features of pancreatic tissue. A: A control animal was sacrificed and histopathology showed normal pancreas; B: Group 2 animals showing normal pancreatic tissue with minor modifications, possibly related to vasodilatation and surgical manipulations; C: Group 1 animals showing a severe form of AP with extensive edema and tissue necrosis; and D: Group 3 animals demonstrating less extensive pancreatic edema and necrosis compared to Group 1 animals.

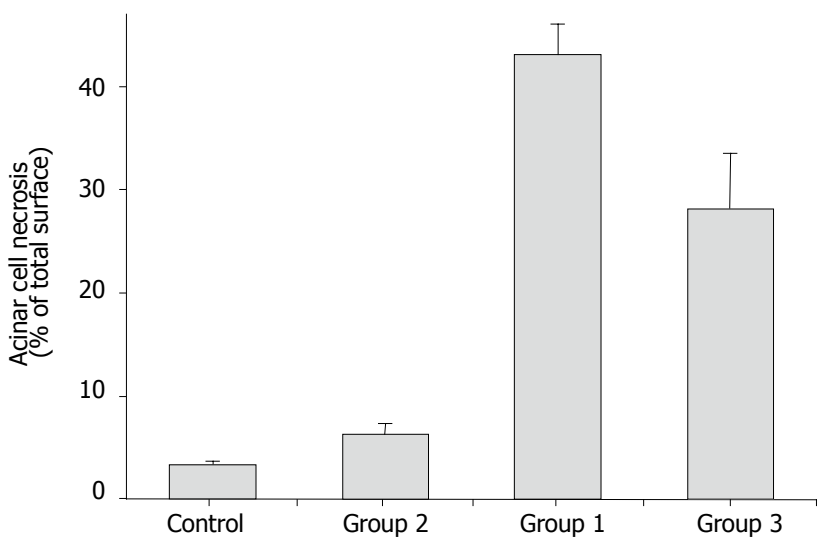

Figure 7 Acinar cell necrosis (percentage of total pancreatic surface). The measure of acinar cell necrosis by percentage of total surface at high power field (HPF) showed that Group 2 animals had similar cell necrosis as the controls $(<10 \%)$. Group 1 animals demonstrated over $40 \%$ acinar cell necrosis at HPF, whereas acinar cell necrosis was below $30 \%$ in Group 3 animals.

concentrations and metabolic acidosis were less severe and the histopathologic scores were improved in comparison to rats with AP and no treatment. These results emphasize the importance of a decreased microcirculatory blood flow in inducing severe AP.

To our best of knowledge, this is the first experimental study showing the beneficial effects of EA on the severity of AP. Previous reports already showed that EA increased splanchnic venous capacitance and decreased arterial tone by blocking sympathetic nerve activity ${ }^{[21,22,28-30]}$. It was also reported that EA might increase sympathetic activity and vasoconstriction in organs distant from the anesthetized area and redistributes blood flow towards splanchnic organs $^{[21]}$.
It has been postulated that several factors, such as local metabolic acidosis which activates various proteases, oxygen-free radical that injures endothelium and parenchyma, or the incapacity of plasma protease inhibitors to circulate through acinar cells, participate in the modifications of pancreatic microcirculation during $\mathrm{AP}^{[3]}$. These modifications result in diminished intravascular volume, chemically-induced vasoconstriction, intravascular coagulation, and increased endothelial permeability ${ }^{[31]}$. Finally, pancreatic ischemia, as a consequence of all these local effects, may convert a mild disease to a severe AP with parenchymal necrosis ${ }^{[31]}$. This has been demonstrated by Klar et al ${ }^{[5]}$ who have shown in anesthetized rabbits that pancreatic blood flow increases when AP is edematous (cerulein injection), whereas pancreatic blood flow decreases when AP is severe (necrotizing form induced by taurocholate injection).

In our study, EA decreased serum amylase concentrations, metabolic acidosis, and the severity of pancreatic necrosis score in comparison to rats that had similar taurocholic acid injection and no treatment. Similar benefit of peridural anaesthesia has been shown on metabolic acidosis during hypoxia in $\operatorname{dog} \mathrm{s}^{[29]}$.

In conclusion, the current study has shown that EA improves the pancreatic hypoperfusion induced by AP with a concomitant decrease in the severity of metabolic acidosis and a diminished tissue injury. EA should therefore be considered a new therapeutic approach to prevent the progression from an edematous disease to a necrotizing AP.

\section{ACKNOWLEDGEMENTS}

The authors thank Martha Jordan for excellent technical assistance. 


\section{REFERENCES}

1 Beger HG, Rau B, Isenmann R. Prevention of severe change in acute pancreatitis: prediction and prevention. J Hepatobiliary Pancreat Surg 2001; 8: 140-147

2 Bradley EL 3rd. A clinically based classification system for acute pancreatitis. Summary of the International Symposium on Acute Pancreatitis, Atlanta, Ga, September 11 through 13, 1992. Arch Surg 1993; 128: 586-590

3 Plusczyk T, Westermann S, Rathgeb D, Feifel G. Acute pancreatitis in rats: effects of sodium taurocholate, CCK-8, and Sec on pancreatic microcirculation. Am J Physiol 1997; 272: G310-G320

4 Dobosz M, Hac S, Mionskowska L, Dobrowolski S, Wajda $Z$. Microcirculatory disturbances of the pancreas in ceruleininduced acute pancreatitis in rats with reference to L-arginine, heparin, and procaine treatment. Pharmacol Res 1997; 36: 123-128

5 Klar E, Schratt W, Foitzik T, Buhr H, Herfarth C, Messmer K. Impact of microcirculatory flow pattern changes on the development of acute edematous and necrotizing pancreatitis in rabbit pancreas. Dig Dis Sci 1994; 39: 2639-2644

6 Schilling MK, Redaelli C, Reber PU, Friess H, Signer C, Stoupis C, Buchler MW. Microcirculation in chronic alcoholic pancreatitis: a laser Doppler flow study. Pancreas 1999; 19: 21-25

7 Kusterer K, Poschmann T, Friedemann A, Enghofer M, Zendler S, Usadel KH. Arterial constriction, ischemia-reperfusion, and leukocyte adherence in acute pancreatitis. Am J Physiol 1993; 265: G165-G171

8 Letko G, Nosofsky T, Lessel W, Siech M. Transition of rat pancreatic juice edema into acute pancreatitis by single ethanol administration. Pathol Res Pract 1991; 187: 247-250

9 Anderson MC. Venous stasis in the transition of edematous pancreatitis to necrosis. JAMA 1963; 183: 534-537

10 Klar E, Rattner DW, Compton C, Stanford G, Chernow B, Warshaw AL. Adverse effect of therapeutic vasoconstrictors in experimental acute pancreatitis. Ann Surg 1991; 214: 168-174

11 Sanfey H, Cameron JL. Increased capillary permeability: an early lesion in acute pancreatitis. Surgery 1984; 96: 485-491

12 McKay C, Imrie CW, Baxter JN. Mononuclear phagocyte activation and acute pancreatitis. Scand J Gastroenterol Suppl 1996; 219: $32-36$

13 Formela LJ, Galloway SW, Kingsnorth AN. Inflammatory mediators in acute pancreatitis. Br J Surg 1995; 82: 6-13

14 Frossard JL, Hadengue A, Pastor CM. New serum markers for the detection of severe acute pancreatitis in humans. Am J Respir Crit Care Med 2001; 164: 162-170

15 Huch K, Schmidt J, Schratt W, Sinn HP, Buhr H, Herfarth C, Klar E. Hyperoncotic dextran and systemic aprotinin in necrotizing rodent pancreatitis. Scand J Gastroenterol 1995; 30:812-816

16 Schoenberg MH, Buchler M, Younes M, Kirchmayr R, Bruckner UB, Beger HG. Effect of antioxidant treatment in rats with acute hemorrhagic pancreatitis. Dig Dis Sci 1994; 39: 1034-1040
17 Paszkowski AS, Rau B, Mayer JM, Moller P, Beger HG. Therapeutic application of caspase 1 /interleukin-1beta-converting enzyme inhibitor decreases the death rate in severe acute experimental pancreatitis. Ann Surg 2002; 235: 68-76

18 Norman J. The role of cytokines in the pathogenesis of acute pancreatitis. Am J Surg 1998; 175: 76-83

19 Steinbrook RA. Epidural anesthesia and gastrointestinal motility. Anesth Analg 1998; 86: 837-844

20 Tuman KJ, McCarthy RJ, March RJ, DeLaria GA, Patel RV, Ivankovich AD. Effects of epidural anesthesia and analgesia on coagulation and outcome after major vascular surgery. Anesth Analg 1991; 73: 696-704

21 Sielenkamper AW, Eicker K, Van Aken H. Thoracic epidural anesthesia increases mucosal perfusion in ileum of rats. Anesthesiology 2000; 93: 844-851

22 Ai K, Kotake Y, Satoh T, Serita R, Takeda J, Morisaki H. Epidural anesthesia retards intestinal acidosis and reduces portal vein endotoxin concentrations during progressive hypoxia in rabbits. Anesthesiology 2001; 94: 263-269

23 Bernhardt A, Kortgen A, Niesel HCh, Goertz A. [Using epidural anesthesia in patients with acute pancreatitis--prospective study of 121 patients]. Anaesthesiol Reanim 2002; 27: 16-22

24 Grouls RJ, Meert TF, Korsten HH, Hellebrekers LJ, Breimer DD. Epidural and intrathecal n-butyl-p-aminobenzoate solution in the rat. Comparison with bupivacaine. Anesthesiology 1997; 86: 181-187

25 Aho HJ, Koskensalo SM, Nevalainen TJ. Experimental pancreatitis in the rat. Sodium taurocholate-induced acute haemorrhagic pancreatitis. Scand J Gastroenterol 1980; 15: 411-416

26 Frossard JL, Kwak B, Chanson M, Morel P, Hadengue A, Mach F. Cd40 ligand-deficient mice are protected against cerulein-induced acute pancreatitis and pancreatitis-associated lung injury. Gastroenterology 2001; 121: 184-194

27 Phillips AR, Farrant GJ, Abu-Zidan FM, Cooper GJ, Windsor JA. A method using laser Doppler flowmetry to study intestinal and pancreatic perfusion during an acute intestinal ischaemic injury in rats with pancreatitis. Eur Surg Res 2001; 33: $361-369$

28 Hogan QH, Stekiel TA, Stadnicka A, Bosnjak ZJ, Kampine JP. Region of epidural blockade determines sympathetic and mesenteric capacitance effects in rabbits. Anesthesiology 1995; 83: 604-610

29 Shibata K, Taki Y, Futagami A, Yamamoto K, Kobayashi T. Epidural anesthesia modifies cardiovascular responses to severe hypoxia in dogs. Acta Anaesthesiol Scand 1995; 39. 748-753

30 Yano $\mathbf{H}$, Takaori $\mathrm{M}$. The microcirculation during enflurane and isoflurane anaesthesia in dogs. Can J Anaesth 1994; 41: 149-155

31 Buchler M, Friess H, Uhl W, Beger HG. Clinical relevance of experimental acute pancreatitis. Eur Surg Res 1992; 24 Suppl 1: $85-88$ 